\section{QIJEI}

International Journal for Educational Integrity

\title{
Editorial, Volume 10(2)
}

Welcome to the last issue of the International Journal for Educational Integrity for 2014 , and the last time the journal will be independently published using the Open Journal System. I am pleased to report that from 1 January 2015, the IJEI will be officially published by Springer. While the journal will remain Open Access, this is a very important step forward for the IJEI, which was established in 2005. In addition to providing very much needed administrative and editorial support, Springer will also provide many advantages, including: 1 . Increased journal ranking and status; 2 . Longterm sustainability; 3 . Increased marketing; and 4 . An anticipated improvement in the quality of submissions. I will continue as Executive Editor and hope to entice new members to the Editorial Board from a range of institutions and disciplines.

This issue, like so many during the last decade, is an eclectic mix of papers from a variety of countries and disciplinary perspectives, and provides unique viewpoints on the meaning and implementation of educational/academic integrity.

Opening the issue, Colin James (University of Newcastle, Australia) and Saadia Mahmud (formerly of University of South Australia) demonstrate that law students are a 'special case' in academic integrity education. Reporting on data from interviews with 12 legal academics who participated in the Australian Academic Integrity Standards Project, James and Mahmud maintain that there are significant and longterm consequences of academic integrity investigations for law students. The authors propose increased clarity and uniformity in the rules of disclosure for graduating law students, as well as an approach which situates academic integrity education as "emergent professional integrity".

Minka Rissanen and Erika Lofstrom, both from the University of Helsinki, Finland, extend their thinking from a paper delivered at the $3^{\text {rd }}$ World Research Integrity Conference (2013), which explored the ability of students to identify ethical issues in research and the role that the learning environment played in the process. Based on relatively small sample of 87 , largely comprised of female students, the authors found no statistically significant relationships between ethical sensitivity, empathy, and the experience of ethical aspects in the learning climate, no difference between psychology and educational science students in terms of their ethical competencies, and no relationship between age and ethical sensitivity. Given the limitations of their own sample, Rissanen and Lofstrom call for more research which investigates the role of learning environments to support and develop students' research ethics.

Moving from disciplinary and pedagogic issues to the broader institutional context, Michael Bath, Peter Hovde and former students of Concordia College in Minnesota, USA, hypothesised that the influences unique to a small, church-affiliated liberal arts college would have a discernible impact on cheating attitudes and practices. Their analysis of data from two student surveys in 2008 and 2010 demonstrates that in fact, the "small college culture" of Concordia College was only partially effective in discouraging academic dishonesty, and that the impact of the religion requirement was insignificant. The authors conclude that in light of the finding that cheating behaviours and attitudes at Concordia College are generally similar to larger, more "impersonal" institutions, the College should consider adopting a formal Honor Code, in line with recommendations by Don McCabe and colleagues.

The International Journal for Educational Integrity is available online at:

http://www.ojs.unisa.edu.au/journals/index.php/IJEl/

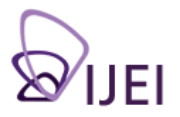


Greg Wheeler, from Sapporo Medical University, Japan, takes the debate a step further and examines the broader culture and its impact on students' attitudes to plagiarism. Using data from a survey administered to students at eight Japanese universities $(n=483$ ), Wheeler challenges the perceived wisdom that students from South East Asian countries are unaware that copying without appropriate attribution is a breach of academic integrity. He concludes that "Japanese students almost overwhelmingly view plagiarism as wrong and believe in the importance of providing citations to works they have used", with the exception of Medical students who appeared to place less emphasis on the importance of citation than students in other disciplines, including Health Sciences. Furthermore, and in sharp contrast with previous research, Wheeler found that the majority of Japanese students are, in fact, provided with instruction on citation techniques. Wheeler's article makes an important contribution to ongoing discussions about the role of culture in students' understandings of academic conventions, and has the potential to have a direct impact on teaching and learning practises, as well as universities' responses to student plagiarism.

The final paper in this issue by Amanda Sladek from the University of Kansas, USA, offers a novel perspective on the meaning of educational integrity. The author interrogates how narratives of for-profit education contribute to public perceptions of institutional integrity, while exploring the complex role that audience plays in the consumption and production of these narratives. Sladek's analysis draws on the case of Dana College, a small non-profit liberal arts college that suspended operations in 2010 after an unsuccessful attempt to transfer ownership to a for-profit entity. Using recent theories in Rhetoric and Composition, Sladek invites the reader "to use the contested and contentious nature of for-profit education as a way to renegotiate what global education will look like in the years to come".

On that challenging note, I will end by wishing you all the best for a stimulating read of this last issue to be published by the Open Journal System. I look forward to continuing to contribute to this fascinating field of inquiry in 2015 as Executive Editor of the International Journal for Educational Integrity, published by Springer.

Tracey Bretag, Editor

November 2014 